\title{
El capital social cooperativo como manifestación del principio de participación económica. Análisis teórico-legal en Cuba
}

(The cooperative's share capital as a manifestation of the principle of economic participation. Legal analysis in Cuba)

Yulier Campos Pérez

Universidad Central «Marta Abreu» de las Villas. Santa Clara (Cuba)

Sumario: I. Introducción. II. Los principios cooperativos: su influencia en el régimen económico de las cooperativas. III. El principio de participación económica de los socios. IV. El capital social cooperativo como manifestación concreta de la participación económica de los socios. V. El capital social cooperativo en la legislación cubana. VI. Conclusiones. VII. Bibliografía y legislación.

Summary: I. Introduction. II. The cooperative principles: their influence on the cooperatives economic system III. The principle of member economic participation. IV. The cooperative's share capital as a manifestation of the member economic participation. $V$. The cooperative's share capital in the Cuban law. VI. Conclusions. VII. Bibliography and legislation.

Resumen: El presente artículo se centra en el análisis del capital social cooperativo en Cuba como manifestación concreta del principio de participación económica de los socios. En el comienzo se detallan los principios cooperativos aprobados por la Alianza Cooperativa Internacional (ACI) y particularmente su influencia en el régimen económico cooperativo. En lo adelante se explica de manera particular la participación económica de los socios como nota distintiva de las cooperativas y que tiene en la conformación del capital social una de sus formas concretas de expresarse.

Palabras clave: principios cooperativos, participación económica, capital social, aportación.

1 Profesor Auxiliar de Derecho Cooperativo, Derecho de Autor y Propiedad Industrial. Departamento de Derecho. Facultad de Ciencias Sociales. Universidad Central «Marta Abreu» de las Villas. Santa Clara, Cuba. Aspirante al grado de Doctor en Ciencias Jurídicas por la Universidad de la Habana, Cuba. E-mail: ycperez@uclv.edu.cu 
Abstract: The present article centres in the analysis of the cooperative capital share capital in Cuba like concrete demonstration of the principle of economic participation of the partners. In the beginning detail the cooperative principles approved by the International Cooperative Alliance (ACI) and particularly his influence in the cooperative's economic system. In it advance it explains of particular way the economic participation of the partners like distinctive note of the cooperatives and that has in the forming of the share capital one of his concrete forms to express .

Keywords: cooperative's principles, economic participation, share capital, contribution. 


\section{Introducción}

Los principios cooperativos constituyen reglas que organizan y distinguen a las cooperativas, lo que se corrobora en la propia existencia de las cooperativas, su relación con otras cooperativas, el estado, organizaciones, la comunidad, los socios, etc. En torno a estos últimos varios principios se configuran y materializan, por ejemplo, el principio de integración abierta y voluntaria, y el de participación económica.

Pese a que la mayoría de los principios influyen, directa o indirectamente, en el régimen económico cooperativo, el de participación económica tiene una relación específica con este elemento.

La participación económica de los socios demuestra que al formar parte de una cooperativa las personas conjuntamente con su voluntad de asociarse también ponen al servicio de la organización aquellos recursos que esta necesita para funcionar o por lo menos hacerlo mejor.

En Cuba aún no se han delimitado con carácter generalizador las bases jurídicas del fenómeno cooperativo, por tanto, cualquier análisis que contribuya a su futura y correcta materialización es acertado. Sin embargo, lo anterior deberá hacerse sin desconocer el desarrollo doctrinal y legal del fenómeno a nivel internacional, y sin olvidar la evolución del cooperativismo en suelo patrio.

Los principios, y su diseño legal, como reglas primeras del cooperativismo, constituyen elementos obligados al hablar de esta materia, de ahí que es imprescindible explicar su dimensión en Cuba. Específicamente el de participación económica reviste en Cuba especial mención pues una de las debilidades que las cooperativas nacionales poseen es la pobre o simbólica aportación al capital social cooperativo, lo que en su momento puede incidir en el diseño patrimonial colectivo y en la existencia misma de la organización.

\section{Los principios cooperativos: su influencia en el régimen económico de las cooperativas}

La Declaración de Identidad Cooperativa aprobada por la Alianza Cooperativa Internacional $(\mathrm{ACl})$, en Manchester, el 23 de septiembre de 1995 delimita los principios que a continuación se analizan. Para ello se toma en cuenta el alcance de los mismos en la gestión económico-jurídica cooperativa. 


\section{Asociación abierta y voluntaria}

Las cooperativas son organizaciones voluntarias, abiertas a todas las personas capaces de utilizar sus servicios y dispuestas a aceptar las responsabilidades de asociarse, sin discriminaciones raciales, políticas, religiosas, sociales y de género.

Este principio supone, en esencia, dos cuestiones: la primera al carácter voluntario de la cooperativa y segunda a su naturaleza abierta.

Voluntaria pues las personas interesadas en asociarse en cooperativas deben hacerlo sin presiones o condicionamientos externos, los mueve el interés por responder a intereses personales, colectivos y sociales, que no se podrían alcanzar, o por lo menos de igual manera, actuando de modo aislado. Las cooperativas son organizaciones surgidas con un fin de servicio, esto es, creadas para dar satisfacción a las necesidades y aspiraciones económicas, sociales y culturales de la gente. ${ }^{2}$

Por otro lado, la naturaleza abierta de las cooperativas significa que las mismas tienen las puertas abiertas a cualquier persona que desee afiliarse, a condición que cumpla los requisitos delimitados, utilice los servicios que esta presta, efectué —o se comprometa a efectuar- los aportes económicos exigidos y asuma las obligaciones por las operaciones sociales.

Sin embargo, esto no quiere decir que no haya límites de ingreso en las cooperativas; estos estarán dados, por ejemplo, en el propio servicio que preste la organización, en los requisitos técnicos y competencias laborales exigidas a los miembros pero nunca por las condiciones religiosas, sexuales, sociales, raciales de los individuos. ${ }^{3}$

Por otra parte, de la misma forma en que las cooperativas están abiertas al ingreso de nuevos miembros, también podrán decidir la expulsión de alguno de sus socios. Los procedimientos para aceptar o expulsar a un socio deben estar claramente establecidos en el norma

2 REYES LAVEGA, S.: Las especiales características de las cooperativas. Fundación Friedrich Ebert, República Dominicana, 2012. p. 4.

3 Lo expresado en el texto está en concordancia con lo dispuesto por la Convención Universal de los Derechos Humanos que manifiesta lo siguiente:

Art. 2.1. Toda persona tiene todos los derechos y libertades proclamados en esta Declaración, sin distinción alguna de raza, color, sexo, idioma, religión, opinión política o de cualquier otra índole, origen nacional o social, posición económica, nacimiento o cualquier otra condición. 
interna de la cooperativa, sin perjuicio a lo que establezca en este sentido la ley.

Con respecto a este elemento ha dicho DABORMIDA que responde mejor a la realidad, la expresión de "puerta semi-cerrada» que da una mejor idea de una tendencial apertura a todos aquellos que son portadores de la misma necesidad económica, dentro de los límites de la eficiencia productiva y de la gestión administrativa. ${ }^{4}$

Ambos supuestos, (ingreso y salida del socio) tendrán influencia sobre el capital social y patrimonio pues este se conforma, en esencia, de las aportaciones de los socios, las que se exigen a aquellos que ingresen a la cooperativa sea en el momento de la constitución o posteriormente.

Por otra parte, la salida de la cooperativa, puede implicar — de reconocerse en la legislación general o en los estatutos- el reembolso de lo aportado. Ambas situaciones son modificativas del elemento subjetivo y esto, en consecuencia, provoca una variación en el componente económico de la cooperativa.

\section{Control democrático por los asociados}

Las cooperativas son organizaciones democráticamente administradas por sus asociados, quienes participan activamente en la fijación de políticas y en la toma de decisiones. Los hombres y mujeres elegidos como representantes son responsables ante los asociados. En las cooperativas primarias los asociados tienen iguales derechos de voto (un asociado, un voto) y las cooperativas de otros niveles se organizan asimismo en forma democrática.

Este principio implica la creación de espacios para la participación de los socios en la toma de decisiones como miembros de la Asamblea General de cooperativistas...5. Refuerza entonces, el gobierno democrático de la cooperativa, expresado en la toma de decisiones de forma colegiada, en la fijación de proyecciones futuras y en la responsabilidad de los directivos de una cooperativa ante todos los socios.

4 DABORMIDA, R.: La disciplina degli organi sociali. Cooperative, consorzi, reaggruppamenti. Ipsoe, Roma, 1999. S/p.

5 VILLEGAS CHADEZ, R.: El desarrollo del movimiento cooperativo en Cuba a la luz de los postulados de la Alianza Cooperativa Internacional (ACI). Revista de Estudios Cooperativos No 63. ISSN: 1885-8031. Madrid, 1997. p. 8. 
El órgano máximo de decisión es la Asamblea General de todos los asociados. ${ }^{6}$ La Asamblea General ${ }^{7}$ en las cooperativas es el órgano decisorio supremo, es competente para conocer y resolver sobre las cuestiones colectivas de mayor importancia.

No obstante, en la mayoría de los casos — sobre todo en las grandes cooperativas - se escoge un órgano ejecutivo, competente para resolver cuestiones igualmente relevantes; no obstante el mismo deberá rendir cuenta ante los asociados sobre su gestión y de esta forma lograr que se mantenga el indicado control democrático.

Igual posibilidad tienen los socios de evaluar el desempeño de las personas que ocupen responsabilidades directivas dentro de la cooperativa, a fin de determinar si la labor de estos ha resultado eficaz.

Otra forma de manifestarse este principio es el hecho de que en las cooperativas cada socio tiene derecho a un voto (un socio un voto), elemento este que permite diferenciarlas de las entidades mercantiles capitalistas, donde por regla general, la participación de los socios dependerá, en esencia, de las aportaciones al capital social colectivo, se constituyen intuitu pecuniae, en la que apenas juegan ni interesan las condiciones personales de los socios, sino la participación que cada uno tenga en el capital social. ${ }^{8}$ Lo aportado determina el alcance de los derechos del socio. Por oposición en las cooperativas todos los asociados poseen idénticos derechos 9 .

6 INTENDENCIA DE CANELONES. Manual para cooperativas de trabajo asociado. Bases para la organización de una cooperativa de producción. Montevideo. Industria Gráfica Cooperativa (INGRACO), 2010. p. 20.

7 En este sentido la Ley marco para las cooperativas de América Latina (2009) establece en el artículo 50: La asamblea es la autoridad máxima de la cooperativa y sus decisiones son obligatorias para el consejo de administración, la junta de vigilancia y todos los socios, presentes o ausentes, siempre que se hubieran adoptado en conformidad con la ley, el estatuto y los reglamentos.

En igual sentido la LEI N. ${ }^{\circ} 5.764$ del 16 de dezembro de 1971 en Brasil norma lo siguiente:

Articulo 38. A Assembléia Geral dos associados é o órgão supremo da sociedade, dentro dos limites legais e estatutários, tendo podêres para decidir os negócios relativos ao objeto da sociedade e tomar as resoluções convenientes ao desenvolvimento e defesa desta, e suas deliberações vinculam a todos, ainda que ausentes ou discordantes.

8 URÍA, R.: Derecho Mercantil. Editorial Marcial Pons, Madrid, 1997. p. 226.

9 La Ley General de Cooperativas de Chile, de 4 de noviembre de 2002, reconoce en el artículo 1 que los socios tienen iguales derechos y obligaciones, un solo voto por persona... Por su parte la Ley de Cooperativas en Canadá « Canada Cooperatives Act» de 20 de octubre de 2010 refiere en su numeral 7 Cooperative Basis inciso b) que todos los socios poseen un solo voto. 
Esta regla posee una doble significación en torno a la participación económica: de un lado configura una de las notas distintivas de las cooperativas frente a las sociedades mercantiles clásicas y por otro lado entre las cuestiones que normalmente son competencia de la asamblea general de asociados está la posibilidad de variar el monto del capital social, exigir nuevas aportaciones, etc.

3. Participación económica de los asociados

Este principio será analizado en un acápite independiente.

\section{Autonomía e independencia}

Las cooperativas son organizaciones autónomas de autoayuda gestionadas por sus socios. Si intervienen en acuerdos con otras organizaciones, incluidos los gobiernos, o captan capital de fuentes externas, lo hacen en términos que aseguran el control por parte de los socios y mantienen su autonomía cooperativa.

Esta regla posee un valor extraordinario pues aunque en estricto sensu constituye una consecuencia de la personalidad jurídica, en realidad su valía no es meramente jurídica-formal sino real ya que expresa la necesidad de que los asociados posean el verdadero control en la actividad cooperativa, sin influencias ni presiones externas. Prueba de la personalidad jurídica, es también, la posibilidad que tiene la cooperativa de poseer patrimonio propio base de todo el régimen patrimonial colectivo.

Este principio se centra fundamentalmente en la relación de las cooperativas con los gobiernos nacionales y las organizaciones gubernamentales internacionales, aunque también tiene implicaciones respecto a la relación entre cooperativas y otras entidades comerciales, como pueda ser un prestamista bancario que aporta bienes a una cooperativa, o proveedores y demás agentes en una posición dominante dentro de la cadena de valor.

Así, la Recomendación 193-Recomendación sobre la promoción de cooperativas, de fecha 20 de junio de 2002, de la Organización Internacional del Trabajo recomienda a los gobiernos establecer una política y un marco jurídico favorables a las cooperativas y compatibles con su naturaleza y función, e inspirados en los valores y principios cooperativos, el mismo debe alentar el desarrollo de las cooperativas como em- 
presas autónomas y autogestionadas, en especial en los ámbitos donde las cooperativas han de desempeñar un papel importante o donde ofrecen servicios que, de otra forma, no existirían. ${ }^{10}$

La anterior no significa que el gobierno no controle u organice a las cooperativas, así como su entorno institucional y jurídico, en realidad el estado debe establecer un marco jurídico que permita organizar a las cooperativas y/o entidades de este sector, por ejemplo, con respecto al registro de la personalidad jurídica, la tributación, el acceso a políticas públicas. No obstante, existen determinadas cuestiones que deben quedar al arbitrio de las cooperativas, entre estas se incluye la elección de los representantes y directivos, el establecimiento de reservas voluntarias, remuneración al capital social, la retribución a los asociados, entre otras. Estos elementos que se relacionan con la participación de los socios, por regla general, quedan al arbitrio de la cooperativa, y solo se enuncian con carácter general en las leyes.

Un elemento que manifiesta la autonomía cooperativa, con carácter general, es la posibilidad de aprobar sus estatutos, estos organizan la actividad de la persona jurídica, concretando o ampliando lo que la norma jurídica dispone. Por regla general las leyes establecen con carácter obligatorio los elementos que no deben faltar en los estatutos, lo que no significa que de manera facultativa las cooperativas delimiten otros por interés particular. El tema es no contradecir lo que la ley establece. Dentro de los elementos que se suelen incluir en los estatutos está el monto de las aportaciones, sus tipos, la remuneración a estas y su destino en caso de disolución, etc.

Según García Müller ${ }^{11}$ el estatuto constituye el conjunto de normas de rango sub-legal de carácter especial contenidas en el mismo documento constitutivo o en uno posterior, que regula la organización interna, las relaciones entre los miembros y delimita la esfera de competencia, actuación y eficacia de los órganos sociales de la entidad, así como la disolución y liquidación de esta. Es importante señalar que se trata de normas de Derecho que se dan a sí mismos los fundadores de la entidad.

10 Recomendación 193-Recomendación sobre la promoción de cooperativas, de fecha 20 de junio de 2002, de la Organización Internacional del Trabajo.

11 GARCÍA MÜLLER, A.: Derecho Cooperativo y de la Economía Social y Solidaria. Editorial Mérida, Buenos Aires, 2014. p. 92. 


\section{Educación, capacitación e información}

Las cooperativas brindan educación y capacitación a sus socios, representantes elegidos, administradores y empleados, de manera que puedan contribuir efectivamente al desarrollo de ellas. Informan al público en general, particularmente a los jóvenes y a los líderes de opinión acerca de la naturaleza y los beneficios de la cooperación.

La educación es uno de sus principios fundadores. Las normas de conducta originales de los Pioneros de Rochdale, publicadas en el almanaque anual de los Pioneros, exigían: «Que un porcentaje fijo del excedente debe destinarse a educación». El compromiso con la educación ha sido uno de los principios fundamentales del movimiento cooperativo desde que éstos se formularon por primera vez.

Este principio es conocido como la «regla de oro» del cooperativismo, porque no solo distingue esta forma organizativa, sino que permite que estas funcionen más eficazmente. La gestión de las cooperativas deben basarse en la educación, el conocimiento, la información, debe estar presente desde el momento de constitución de la persona jurídica; los futuros socios deben estar educados en los principios del cooperativismo, los métodos de organización, etc. El nivel de formación de los asociados supone una garantía para el éxito de la cooperativa, no solo desde lo social sino también desde el punto de vista económico.

Como señalan KaPLAN DE DRIMER Y DRIMER ${ }^{12}$ se trata de una norma fundamental que deriva de la naturaleza misma de la institución cooperativa. Desde el punto de vista práctico cabe observar que las cooperativas en su carácter de entidades socioeconómicas basadas en el esfuerzo propio y la ayuda mutua de los asociados, colocan en manos de estos últimos (por sí mismos o a través de los representantes elegidos entre ellos) funciones de deliberación general, dirección y control interno de las actividades; de modo que los asociados han de adquirir los conocimientos que les permitan cumplir acertadamente sus importantes funciones.

Unido a lo anterior desde el punto de vista moral, en su carácter de asociaciones de personas que aspiran a regir sus relaciones socioeconómicas en base a normas de igualdad, solidaridad, justicia y equidad; las cooperativas necesitan difundir el espíritu cooperativo a través de la educación.

12 KAPLAN DE DRIMER, A. y DRIMER, B.: Las cooperativas. Fundamentos, historia, doctrina. Intercoop, Buenos Aires, 1981. 
Visto así, esta regla se estructura hacia dos ámbitos fundamentales, el primero y más importante en relación al conocimiento de la gestión cooperativa, sus principios y formas de funcionamiento, pero en segundo lugar es trascendente el conocimiento de la actividad en que la cooperativa y sus asociados se desenvuelven, en correspondencia con su objeto social, es decir la necesaria formación técnica-profesional de los asociados.

La educación de manera general constituye un presupuesto para que cualquier proyecto sea exitoso, la necesidad de su reconocimiento como principio nació en países donde no constituye un derecho fundamental y general garantizado a todos los ciudadanos. ${ }^{13}$

La relación entre la educación y la participación económica se configura en la posibilidad que tienen las cooperativas en establecer fondos destinados al fomento de la educación, así como que en el caso de disolución parte del patrimonio es irrepartible entre los asociados y puede tener entre otros destinos impulsar la formación en cooperativas.

\section{Cooperación entre cooperativas}

Las cooperativas sirven más efectivamente a sus socios y fortalecen al movimiento cooperativo trabajando mancomunadamente a través de estructuras locales, nacionales, regionales e internacionales.

Las cooperativas no solo aplican valores como la solidaridad y la ayuda mutua a lo interno, sino que esto debe proyectarse además a lo externo, en sus relaciones con otras cooperativas. Esto favorece el ambiente cooperativo, hace que más personas conozcan de la forma de gestión de las cooperativas, máxime si con las relaciones que se establezcan se logran resultados positivos.

13 La Declaración Universal de los Derechos Humanos reconoce el mismo como un derecho humano, al respecto manifiesta en el art. 26 que:

1. Toda persona tiene derecho a la educación. La educación debe ser gratuita, al menos en lo concerniente a la instrucción elemental y fundamental. La instrucción elemental será obligatoria. La instrucción técnica y profesional habrá de ser generalizada; el acceso a los estudios superiores será igual para todos, en función de los méritos respectivos.

2. La educación tendrá por objeto el pleno desarrollo de la personalidad humana y el fortalecimiento del respeto a los derechos humanos y a las libertades fundamentales; favorecerá la comprensión, la tolerancia y la amistad entre todas las naciones y todos los grupos étnicos o religiosos, y promoverá el desarrollo de las actividades de las Naciones Unidas para el mantenimiento de la paz. 
Este principio exhorta de forma explícita a la cooperación entre cooperativas. La autoayuda es uno de los pilares del movimiento cooperativo y la autoayuda a través de la cooperación entre cooperativas es una parte crucial de la extensión del sector empresarial cooperativo de la economía, tanto a nivel nacional como mundial. La cooperación entre cooperativas precisará, en ocasiones, de sacrificios para alcanzar metas comunes. Esto puede resultar complicado cuando, por ejemplo, los intereses mutuos y colectivos tienen más peso que lo que podría beneficiar a una sola cooperativa en concreto y a corto plazo ${ }^{14}$.

Una vía en la que se materializa esta regla es a través de la constitución de las cooperativas de segundo o ulterior grado para, por ejemplo, acceder a servicios a un menor costo. En tales casos se exigirán nuevas aportaciones a los asociados y se materializarán nuevas formas también de retribución personal y colectiva a los mismos.

Además, las cooperativas pueden relacionarse con sus similares a través de la creación de federaciones, asociaciones y confederaciones.

Cabe apuntar que en todos los casos se garantizará el respeto de los principios hasta aquí explicados, en especial la gestión democrática, el control de los asociados y la autonomía e independencia.

\section{Compromiso con la comunidad}

Las Cooperativas trabajan para el desarrollo sostenible de la comunidad donde funcionan.

Este principio refuerza el compromiso social de la cooperativa al establecer que esta trabaja por el desarrollo sostenible de la comunidad, es decir trabaja por la comunidad pero sin poner en peligro las generaciones futuras, ni el acceso de estas a los recursos naturales. Destaca el contenido ético-social de este postulado, pues aunque las cooperativas son entes autónomos, deben respeto al entorno en el que se desarrollan, respeto en todos los sentidos, en lo personal, histórico, ambiental y social.

Al decir de CARDOSO Y HAMAHN ${ }^{15}$ las cooperativas, como organizaciones de personas, tienden a estar vinculadas estrechamente a la comunidad donde los cooperadores residen.

14 ALIANZA COOPERATIVA INTERNACIONAL.: Notas de orientación para los principios cooperativos, 2015. p. 92.

15 CARDOSO, A. y HAMAHN, M.: Principios cooperativos: origem, evolução e influencia na legislação brasileira. III Encuentro de Investigadores en cooperativismo. Porto Alegre. Unisinos, 2004. p. 14. 
Este principio combina dos elementos de los valores cooperativos reconocidos en la Declaración sobre la Identidad Cooperativa de la Alianza: los de «autoayuda y responsabilidad propia» y «los valores éticos de honestidad, apertura, responsabilidad social y preocupación por los demás».

La cooperativa a través del trabajo que realizan sus miembros puede destinar parte de este o sus beneficios económicos en pos de la comunidad, lo que concreta su fin social y responsabilidad con el medio.

Luego de este análisis puede sostenerse que los principios cooperativos establecidos por la Alianza Cooperativa Internacional constituyen reglas que contribuyen a unificar a las cooperativas, las caracterizan y trascienden a su identidad. Aun y cuando están referidos a todos los ámbitos en que estas se desarrollan, de manera directa o no trascienden a su gestión económica y ordenan la participación de los asociados en este sentido.

\section{El principio de participación económica de los socios}

Como se enunciaba antes, el tercer principio establece la participación económica de los socios, cuestión que se materializa entre otros supuestos, en el capital social. Por este motivo se analiza aquí en un acápite específico. Este se enuncia de la siguiente forma:

Los asociados contribuyen equitativamente a la formación del capital de su cooperativa y lo administran democráticamente. Por lo general, al menos una parte de ese capital es propiedad común de la cooperativa. Los asociados suelen recibir una compensación limitada, si acaso alguna, sobre el capital suscripto como condición para asociarse. Destinan los excedentes a todos o alguno de los siguientes fines: el desarrollo de la cooperativa, posiblemente mediante la constitución de reservas de las cuales una parte al menos debe ser indivisible; la distribución a los asociados en proporción a sus operaciones con la cooperativa y el apoyo a otras actividades aprobadas por los asociados.

Este principio contiene un conjunto de elementos que complementan al anterior (control democrático), quedando reforzados los siguientes conceptos: ${ }^{16}$

a) El control democrático, en este caso haciendo referencia más específicamente al patrimonio de la cooperativa.

16 REYES LAVEGA, S.: ob. cit., p. 7. 
b) La inexistencia de fin de lucro de las cooperativas.

c) El carácter instrumental del capital social.

d) La necesidad de conformar reservas indivisibles e irrepartibles.

Los miembros de una cooperativa participan económicamente en dos sentidos; primero aportando al patrimonio de la cooperativa y luego beneficiándose de la gestión económica desarrollada por esta.

La aportación es la contribución de una determinada prestación patrimonial que debe cumplir el socio para formar el capital social de la cooperativa y adquirir su condición de tal.

El aporte económico efectuado que le atribuye la condición de miembro, hace que ese momento, esa contribución, sea considerada como un acto cooperativo preparatorio de los actos cooperativos estrictamente dichos. Entonces, el efecto de que sea un acto cooperativo (aunque preparatorio) es que como tal, queda regulado en primer lugar por la normativa cooperativa, ya sea en la ley, estatuto o reglamento interno y sólo de manera supletoria por la norma genérica de la actividad.

Los asociados controlan el capital en sus cooperativas de dos for$\operatorname{mas}^{17}$ :

1. Sin importar cómo las cooperativas obtienen el capital para sus operaciones, la autoridad final para la toma de decisiones debe recaer sobre los asociados. ${ }^{18}$ Los asociados deben tener derecho a poseer por lo menos parte de su capital colectivo, como reflejo de lo que han obtenido como grupo.

2. Cuando las actividades de la cooperativa crean excedentes, los asociados tienen el derecho y la obligación de decidir cómo son distribuidos esos excedentes. Los asociados pueden asignar tales excedentes para cualquiera de los siguientes propósitos:

a) Los asociados pueden elegir el desarrollo de la cooperativa, a través de la creación de reservas, parte de las cuales son indivisibles, en correspondencia con la legislación interna de cada estado. Este planteamiento, en muchas cooperativas, debe ser la forma normal para asignar los excedentes que no son devueltos a los asociados, y asegurar la viabilidad de largo plazo de la cooperativa.

17 CENTRO DE ESTUDIOS Y CAPACITACIÓN COOPERATIVA.: Doctrina cooperativa. Programa de educación a distancia administración de empresas cooperativas. Costa Rica, 2005. s/p.

18 Normalmente la Asamblea General como órgano superior de la cooperativa. 
b) Los asociados pueden decidir pagar un beneficio, usualmente llamado «excedente o utilidades», en proporción con la participación en la cooperativa. Esta es la forma tradicional para recompensar a los asociados por su apoyo a la cooperativa. Los asociados también pueden apoyar otras actividades según lo apruebe la asamblea. Se manifiesta aquí la conjugación control democrático — participación económica pues los asociados participan en materia económica pero con aprobación de la asamblea, órgano superior democrático de la cooperativa-.

Constituye una nota distintiva en estas formas de organización el hecho de que en caso de disolución de la cooperativa los restos luego de liquidar las deudas de la misma (con los miembros y terceros), no son apropiables por los socios, sino que en sentido general se utilizan para otras actividades como el fomento del cooperativismo y el mejoramiento de las condiciones de la comunidad, elementos estos que complementan otros principios y refuerzan la función social de la cooperativa.

En otro sentido de la retribución económica, los miembros de una cooperativa «participan» de los resultados de su gestión fundamentalmente mediante tres vías: el anticipo, el retorno y los fondos sociales. ${ }^{19}$

Las dos primeras constituyen beneficios personales, pues se configuran en interés del individuo en particular, no así en la tercera de las vías que se configura como una forma de beneficio colectivo.

El anticipo es lo que recibe cada asociado de manera sistemática, este se efectúa en forma inmediata, en el momento de la participación del individuo el objeto social. La persona obtiene en el mismo momento de su participación en la cooperativa una justa retribución por el trabajo que realiza, si es cooperativa de trabajo o de producción agraria, por ejemplo. Es importante, además, delimitar el monto de este, tomando en cuenta la cantidad y calidad del trabajo realizado en relación con la solvencia colectiva, a los efectos de no poner en riesgo o desventaja a la cooperativa.

El retorno, por otro lado, es lo que recibe cada asociado al final de cada ejercicio fiscal si la cooperativa tiene ganancias luego de cumplir con sus obligaciones legales.

19 CRUZ REYES, J. y PIÑEIRO HARNECKER, C. ¿Qué es una cooperativa?, en Cooperativas y socialismo. Una mirada desde Cuba. Editorial Caminos, La Habana, 2011. p. 43. 
Los fondos sociales, como se dijo antes, son utilizados por la colectividad, es decir es el ingreso que beneficia a un número mayor de individuos de forma colectiva, favorece la solidaridad y el trabajo en equipo. Los tipos de fondos varían en dependencia de la legislación vigente en cada país y de los estatutos aprobados por la cooperativa de que se trate. Estos se exigen después de que la cooperativa cumpla con sus obligaciones jurídicas. ${ }^{20}$

La formación de reservas patrimoniales y de fondos sociales es un propósito empresarial de toda cooperativa y una exigencia para cumplir su objeto social, apalancarse y sustentarse. Si no hay excedentes, no hay reservas ni fondos y queda en entredicho la perspectiva empresarial y social21. Los mismos constituyen parte del activo cooperativo, actúan como garantía para los acreedores de la cooperativa y manifiestan desde el punto de vista económico la gestión colectiva de la entidad, sustento en gran medida de la gestión social.

Baste concluir entonces que las reservas constituyen la fuente de financiamiento medular de las cooperativas, por lo cual los excedentes debieran destinarse, en un porcentaje importante, a constituirlas y así fortalecerlas patrimonialmente. Estas, en unión con las aportaciones al capital social y las formas de retribución individual al socio (anticipo y retorno), son las variantes fundamentales a través de las cuales se materializa el principio de participación económica de los asociados.

Seguidamente nos referiremos a una de las instituciones jurídicas a través de las cuales se conforma la participación económica de los asociados: el capital social cooperativo. tablece:

20 En este sentido la Ley Marco para las cooperativas de América Latina, 2009, es-

Artículo 41. Sin perjuicio de la reserva legal las cooperativas podrán, con cargo a los excedentes, crear e incrementar reservas especiales para amparar y consolidar el patrimonio, las que deberán ser expresamente aprobadas por la asamblea.

Artículo 42. Con el objeto de proveer recursos con destinación específica para la prestación de servicios de carácter asistencial, de bienestar social, educativo o de investigación, las cooperativas podrán crear e incrementar fondos especiales con aportes voluntarios $u$ obligatorios de los socios o parte de los excedentes anuales, conforme establezca el estatuto.

21 ZABALA SALAZAR, H.: Defensa de los fondos sociales cooperativos: naturaleza, propósito y necesidad. Asociación antioqueña de cooperativas (CONFECOOP ANTIOQUIA), 2006. Consultado en: https://www.confecoopantioquia.coop/imagenes/ descargas/FONDOSSOCIALES.pdf en fecha 31 de marzo de 2018. p. 6. 


\section{El capital social cooperativo como manifestación concreta de la participación económica de los socios}

La noción jurídica del capital es de interés teórico-práctico y reviste importancia para el normal desenvolvimiento institucional de las cooperativas ${ }^{22}$, de ahí que el régimen del capital sea una cuestión recurrente en las distintas reformas legislativas que para las sociedades cooperativas se han propuesto o aplicado durante los últimos 10/15 años²3.

De manera particular FARRÉs CAVAGNARO Y MENÉNDEZ definen el capital social cooperativo, en los siguientes términos: el capital social es un concepto jurídico, consistente en una cifra que representa la suma de los valores de los aportes de dar en propiedad, comprometidos por los asociados, para que la entidad pueda realizar su objeto. También se ha dicho que se trata de una noción contable de especial interés jurídico, ya que está formado por la suma de los aportes en numerario y especie (obligación de dar) que los socios se comprometen a efectuar, de donde se deduce que es una cifra ideal, es decir, el enunciado numérico del valor que representa aquella suma.

En este sentido la Ley General de Sociedades Cooperativas de 4 de junio de 2001 en México estipula en el Artículo 49 que el capital de las sociedades cooperativas se integrará con las aportaciones de los socios... Igual sistemática sigue la Ley General de Cooperativas refundida y actualizada el 4 de noviembre de 2002 en Chile que dispone en el ar-

22 LUNA, G.F, E.: El capital en las sociedades cooperativas. Boletín de la Asociación Internacional de Derecho Cooperativo No.35, 2001. Consultado en http://baidc. revistas. deusto.es/article/view/896 en fecha 14 de diciembre de 2017. p. 24http://baidc.revistas. deusto.es/article/view/896

23 CELAYA ULLÍBARRI, A.: Criterios básicos para una regulación legal del Capital en las Sociedades Cooperativas. Boletín de la Asociación Internacional de Derecho Cooperativo No.35, 2001. Consultado en http://baidc.revistas.deusto.es/article/view/896 en fecha 9 de diciembre de 2017. p. 11.

El capital social es uno de los aspectos sobre los que más se ha debatido en la elaboración de las últimas legislaciones cooperativas, suscitándose en gran parte como consecuencia de una general constatación de un déficit legal evidente, de una legislación que prácticamente imposibilita la captación y acumulación de recursos de capital a largo plazo, siendo numerosas las propuestas de actualización del régimen legal destinados todos ellos a crear nuevos instrumentos que incentiven la financiación a largo plazo de las cooperativas. A partir de los años 90 se pueden mencionar varias leyes que han regulado esta cuestión, tal es el caso de la Ley $N .^{\circ} 438$ de cooperativas de Paraguay (del 21 de octubre de 1994), en su artículo 39; el Decreto N. ${ }^{\circ} 1.440$ de 30 de agosto de 2001 de Venezuela, en su artículo 46. Ley No. 499 de 2004, de Nicaragua en su artículo 36. Ecuador con su Ley orgánica de la economía popular y solidaria y del sector financiero popular y solidario del 28 de abril de 2011 lo regula en su artículo 49. Ley 27/1999, de 16 de julio, De Cooperativas. España. Arts. 45-54 
tículo 25 que el capital de las cooperativas (...) se formará con las sumas que paguen los socios por la suscripción de sus cuotas de participación.

Según VINCENT Chulí el capital social es el conjunto de las aportaciones de los socios, y para las sociedades cooperativas la suma representativa en el pasivo de las aportaciones de socios y asociados, desembolsadas o prometidas, que funcionan como cifra de retención aunque con carácter relativo ya que el capital es variable. ${ }^{24}$

Explica FAJARDO GARCía que el capital es la cifra contable de naturaleza variable formada por el conjunto de las aportaciones obligatorias de los integrantes de la empresa; la suma que representa el total de los aportes que se hacen a la empresa solidaria y sin los cuales no puede cumplir su objeto; la inversión genuina de los miembros. ${ }^{25}$

Destacar en esta definición el hecho de reconocer el carácter variable del capital, aunque solo se incluyen, incorrectamente, como parte de este a las llamadas aportaciones obligatorias dejando fuera, por tanto, a las llamadas aportaciones voluntarias.

Por su parte Althaus expresa que el capital es una forma de propiedad individual, ya que si bien los fondos aportados pasan a ser propiedad de la empresa, los miembros pasan a ser propietarios, por su parte, de las cuotas que expresan su participación patrimonial en la misma, que permanecen en su activo personal: engendran derechos de contenido patrimonial en su favor. ${ }^{26}$

Aunque puede reconocerse un interés limitado al capital y/o devolución del aporte realizado, no puede considerarse que este sea una forma de propiedad individual pues en realidad pertenece a la cooperativa como parte de su patrimonio y aunque el socio pudiera recuperarlo, siempre lo hará bajo determinadas condiciones que no pongan en riesgo la organización colectiva.

Entonces, luego de analizadas las anteriores definiciones puede sostenerse que el capital social cooperativo constituye la suma de las aportaciones, obligatorias y voluntarias, de los asociados ya sea en el momento de la constitución de la misma o posteriormente, bien por la

24 VINCENT CHULIÁ, F.: citado por GÓMEZ APARICIO, P.: El capital social en las sociedades cooperativas. Las normas sobre los aspectos contables de las sociedades cooperativas a la luz de los principios cooperativos. CIRIEC-España, Revista de Economía Pública, Social y Cooperativa, n. ${ }^{\circ} 45,2003$. Consultado en: http://www. ciriecrevista economia.es/banco/03_Gomez_45.pdf en fecha 12 de noviembre de 2017.http://www. ciriec-revistaeconomia.es/banco/03_Gomez_45.pdf

25 GARCÍA MÜLLER, A.: ob. Cit. p. 27.

26 GARCÍA MÜLLER, A.: ob., Cit. p. 432. 
incorporación de nuevos miembros o como consecuencia de acuerdos de aumento de capital.

Constituye, entonces, una forma concreta de manifestarse el principio de participación económica de los socios pues con su formación los socios comprometen no solo su persona con la cooperativa sino también sus recursos económicos.

Hay consenso doctrinal (Rippe, Acera Manero, Lacalle Olano, Fajardo, García Müller, Amorín y Algorta Morales) y legal (Finlandia, España, Uruguay, Argentina, Brasil, Ecuador, Portugal) en considerar como caracteres del capital social cooperativo su variabilidad e ilimitación.

Estos caracteres constituyen consecuencias del principio de asociación abierta y voluntaria pues la variación del número asociados, conllevará inevitablemente a una variación en el capital social, pues como se dijo antes, este lo integran las aportaciones que ellos mismos realizan, además los miembros pueden tener derecho al reembolso en caso de baja de lo que un día aportaron. A esto se le une el hecho de que el número de asociados es ilimitado, lo que presupone la ilimitación del capital social.

El capital social es variable e ilimitado y se divide en partes sociales de igual valor, que los asociados suscriben e integran con diversas clases de aportes valuables en dinero, para la constitución del mismo. ${ }^{27}$

Estos aportes constituyen el primer recurso patrimonial con que cuenta la cooperativa, es la contribución inicial a la que se comprometen y obligan los asociados o futuros asociados para hacer funcionar la organización. Constituyen, como se dijo antes, una manifestación de participación económica concreta de los asociados en la gestión cooperativa.

Lo anterior no significa que económicamente sean el recurso de mayor cuantía, puede darse el caso que la cooperativa reciba recursos de otras fuentes ${ }^{28}$ y que, incluso, monetariamente tengan más importancia, sin embargo, por el papel y el lugar que ocupan las aportaciones, se reconoce su alta significación. Nótese que demuestran el compromiso de los miembros a trabajar cooperadamente en la satisfacción de intereses colectivos y personales. Además con esta se adquiere nor-

27 RIPPE, S.: El capital en las cooperativas. Boletín de la Asociación Internacional de Derecho Cooperativo No.35, 2001. Consultado en http://baidc.revistas.deusto.es/article/ view/896 en fecha de octubre de 2016. p 68. http://baidc.revistas.deusto.es/article/ view/896

28 Pueden mencionarse aquí los recursos externos como los obtenidos a través de créditos bancarios, donaciones, etc. 
malmente 29 la condición de socio, excepto en el caso de aquellas que se realicen voluntariamente.

Son aportes sociales comprometidos totalmente con el riesgo de la empresa.

En sentido general, entonces, la formación e integración del capital social cooperativo constituye tal como se dijo antes una de las formas a través de las cuales los asociados participan económicamente en la cooperativa. Este se conforma con las aportaciones de los socios sean estas obligatorias o voluntarias, dinerarias o no. Conjuntamente con otros recursos económicos conforman el patrimonio cooperativo.

\section{Los principios cooperativos en la legislación cubana. Especial atención a la participación económica}

En Cuba, donde el movimiento cooperativo se desarrolló sobre la transformación de las estructuras sociales que posibilitó la Revolución, las bases del cooperativismo partían de una concepción genuinamente socialista ${ }^{30}$. Según Nova Gonzalez el desarrollo del cooperativismo en Cuba es bastante joven, pues este comienza de forma significativa a partir del triunfo revolucionario en $1959^{31}$.

Baste esto para presuponer que las cooperativas en Cuba poseen marcado apego en su origen y desarrollo al llamado "socialismo real» y a la propia Revolución Cubana. Esto presupone que muchas veces las normas cooperativas nacionales posean marcadas diferencias con las delimitadas a nivel internacional, tal es el caso del tema que nos ocupa: los principios cooperativos.

Al decir de Fernández Peiso, con lo que el autor coincide, en Cuba, no están unificados ni sistematizados los principios del cooperativismo nacional. Ello muestra el mandato del Decreto Decreto-Ley nú-

29 Existen entidades colectivas, incluso de carácter solidario, que no exigen aportes (al capital social) a sus miembros. Es lo que sucede en las asociaciones incluso algunas cooperativas - Cooperativas de Créditos y Servicios en Cuba- que no lo establecen en su norma interna, en estas los asociados no hacen aportes sino que financian las actividades de la entidad mediante cuotas periódicas no reintegrables, por ejemplo obtenidas producto de la venta de productos agropecuarios a través de la cooperativa.

30 JIMÉNEZ GUETHÓN, R.: El desarrollo del cooperativismo en Cuba. Consultado en roa.ult.edu.cu/bitstream/123456789/2320/1/art_RJimenez3.pdf en fecha 14 de diciembre de 2017 p. 1.

31 NOVA GONZÁLEZ, A.: Las cooperativas agropecuarias en Cuba: 1959-presente. Parte 4 Las cooperativas y la construcción socialista en Cuba. Consultado en http:// www.actaf.co.cu/revistas/cooperativas/04-12coopsoci-cuba.pdf en fecha $12 \mathrm{~d}$ enero de 2018. p. 1. 
mero 142. "Sobre las Unidades Básicas de Producción Cooperativa» (DL 142/93) de fecha 20 de Septiembre de 1993 que establece, para las UBPC, cuatro principios de la actividad y siete características principales de funcionamiento, mientras Ley No. 95 «Ley de Cooperativas de Producción Agropecuarias y de Créditos y Servicios» (Ley 95/20002) de 2 de noviembre del 2002 apunta 10 principios rectores para las CPA y CCS. A esto se une el hecho de que en las recientes normas que aprueban el cooperativismo no agropecuario (Gaceta Oficial 053 Extraordinaria de 11 de diciembre de 2012.) se establecen 7 principios en los que se sustentan estas cooperativas.

Lo anterior muestra un panorama diverso en el contexto nacional de la regulación de los principios, marcado en gran medida por la tipología de las cooperativas (sean agrarias o no) y por el desarrollo histórico que estas han experimentado a nivel nacional e internacional, pues en la caso de los reconocidos en las normas aprobadas en el 2012 se acercan más a los principios recogidos internacionalmente.

La Ley No. 95/ 2002 reconoce en su artículo 3 que este tipo particular de cooperativas se rige por los principios de voluntariedad, cooperación y ayuda mutua, contribución al desarrollo de la economía nacional, disciplina cooperativista, decisión colectiva, territorialidad, bienestar de los cooperativistas y sus familiares, colaboración entre cooperativas, solidaridad humana e interés social. ${ }^{32}$

32 Ley No. 95 «Ley de Cooperativas de Producción Agropecuarias y de Créditos y Servicios» de 2 de noviembre del 2002, Colectivo de Autores.: Temas de Derecho Agrario Cubano Tomo II. Selección Legislativa de Derecho Agrario Cubano. Volumen 1. Editorial Félix Varela, La Habana, 2007.

Art. 3. Las cooperativas se rigen por los principios siguientes:

a) voluntariedad: la incorporación y permanencia de los miembros de las cooperativas es absolutamente voluntaria;

b) cooperación y ayuda mutua: todos los miembros trabajan y aúnan sus esfuerzos para el uso racional de los suelos y bienes agropecuarios, propiedad o en usufructo de las cooperativas o de los cooperativistas;

c) contribución al desarrollo de la economía nacional: todos los planes y programas de las cooperativas están dirigidos y tienen como objetivo fundamental trabajar por el desarrollo económico y social sostenible de la nación;

d) disciplina cooperativista: todos sus miembros conocen, cumplen y acatan conscientemente, las disposiciones de esta Ley, sus reglamentos, los acuerdos de la Asamblea General y las demás leyes y regulaciones que son de aplicación en las cooperativas;

e) decisión colectiva: todos los actos que rigen la vida económica y social de las cooperativas se analizan y deciden en forma democrática por la Asamblea General y la Junta Directiva, en que la minoría acata y se subordina a lo aprobado por la mayoría; 
Aunque los principios que aquí se recogen no se corresponden exactamente con los aprobados por la $\mathrm{ACl}$, su contenido se relaciona en gran medida con estos presupuestos.

Por tanto la participación económica no se delimita como una regla particular, sin embargo, dentro de los principios recogidos se establecen algunos elementos que apuntan a ella. A criterio de RodríGuez MUSA y a HERNÁNDEZ AgUILAR la presencia de este principio transversaliza a las previsiones legales contenidas en las normas cooperativas nacionales ${ }^{33}$

Por ejemplo, en el principio cooperación y ayuda mutua se reconoce que los miembros trabajan y aúnan sus esfuerzos, sin especificar el alcance de estos esfuerzos, por lo que cabrían aquí las aportaciones al capital pues con estas se demuestra el interés y la voluntad de trabajar colectivamente. La tierra, por lo general, es el bien más valioso de cualquier campesino, y si decidió aportarlo a la cooperativa que mayor prueba de aunar esfuerzos e interés por trabajar unido.

Lo anterior se relaciona directamente con el principio de bienestar de los cooperativistas y sus familiares ya que este reconoce que las cooperativas han de lograr la satisfacción racional de las necesidades materiales, sociales, educativas, culturales y espirituales de sus miembros y familiares.

Dentro de la disciplina cooperativista delimita que los miembros cumplen y acatan conscientemente las disposiciones legales y las inter-

f) territorialidad: los agricultores pequeños se integran y pertenecen a la cooperativa del territorio en que están enclavadas sus tierras, con el fin de facilitar la mejor y más económica gestión de la cooperativa con relación a sus miembros;

g) bienestar de los cooperativistas y sus familiares: las cooperativas trabajan para lograr la satisfacción racional de las necesidades materiales, sociales, educativas, culturales y espirituales de sus miembros y familiares;

h) colaboración entre cooperativas: las cooperativas se prestan colaboración entre sí mediante la compraventa de productos para el autoabastecimiento, pies de cría, semillas, prestación de servicios para la producción, intercambio de experiencias, y otras actividades lícitas sin ánimo de lucro;

i) solidaridad humana: practican la solidaridad humana con sus miembros, trabajadores y demás personas que habiten en las comunidades donde están enclavadas;

j) interés social: todos sus actos y acciones tienen como fin el interés social.

33 RODRÍGUEZ MUSA, O Y HERNÁNDEZ AGUILAR, O.: Reflexiones sobre la implementación jurídica del principio de «participación económica de los asociados» en las cooperativas cubanas. En Boletín de la Asociación Internacional de Derecho Cooperativo no. 52 ISSN-e: 2386-4893, Bilbao, 2018. p. 111 
nas, dentro de las que se incluyen, por supuesto, aquellas referidas a organizar la vida patrimonial de la organización.

En torno al aspecto patrimonial y económico se establece que los actos que rigen la vida económica y social de las cooperativas se analizan y deciden en forma democrática por la Asamblea General y la Junta Directiva. Lo anterior confirma el control democrático de los asociados y se relaciona claramente con el principio de participación económica.

En relación a las Unidades Básicas de Producción Cooperativa, (UBPC) el DL 142/93 establece en su artículo 1 que las mismas se sustentarán en los principios siguientes:

a) la vinculación del hombre al área;

b) el autoabastecimiento del colectivo de obreros y sus familiares con esfuerzo cooperado y el mejoramiento de sus condiciones de vida;

c) los ingresos de los trabajadores estarán asociados rigurosamente a la producción alcanzada; y;

d) desarrollar ampliamente la autonomía de la gestión y administrar sus recursos haciéndose autosuficiente en el orden productivo.

De su lectura es claro que tales disposiciones no se corresponden con las reglas establecidas por la $\mathrm{ACl}$ entre las que se incluye por supuesto el principio de participación económica. No obstante, nada prohíbe tampoco que se realicen aportaciones por los miembros, pues debe primar la autonomía en la gestión, estas contribuirían al desarrollo de la cooperativa.

A nuestro criterio es notable y evidente la lejanía de tales reglas con los postulados declarados internacionalmente; lo que se debe en gran medida al fin de tales organizaciones que al decir de la propia norma es hacer más eficiente la agricultura cañera y no cañera, aplicar fórmulas que incentiven y motiven a los hombres a entregar sus reservas productivas en función de lograr mayores volúmenes de producción con el menor gasto posible de recursos materiales, llevar a cabo importantes innovaciones en la agricultura estatal, mejor utilización y conservación de toda la tierra de la cual sea posesionario, incrementar en ella la producción de alimentos, en fin enfrentar las consecuencias del llamado «período especial» en el que se vio inmerso Cuba tras el derrumbe del campo socialista.

Por sus particularidades se ha discutido la condición de cooperativa de la UBPC, ya que por ejemplo, a los integrantes de esta organización colectiva no se les reconoce la condición de cooperativistas, sino que 
son considerados trabajadores también al hecho de la poca participación de los miembros de las UBPC en la toma de decisiones, y que al interés constitutivo parte del estado y no de los miembros.

Estos elementos trascienden a su funcionamiento, no obstante no se puede negar que aunque con imperfecciones, están integradas por miembros asociados voluntariamente, con autonomía en su gestión y administración de los recursos.

Por su parte el Decreto Ley 305 «De las cooperativas no agropecuarias» de 15 de noviembre de 2012 en el artículo 4 dispone que las cooperativas - estrictamente las no agrarias - se sustentan en los principios de: voluntariedad, cooperación y ayuda mutua, decisión colectiva e igualdad de derechos de los socios, autonomía y sustentabilidad económica, disciplina cooperativista, responsabilidad social, contribución al desarrollo planificado de la economía y al bienestar de sus socios y familiares, colaboración y cooperación entre cooperativas y con otras entidades. ${ }^{34}$

Aunque los dictados de esta norma tampoco se corresponden estrictamente con lo dispuesto por la $\mathrm{ACl}$, dentro de sus reglas al igual

34 Decreto Ley 305 «De las cooperativas no agropecuarias» de 15 de noviembre de 2012. Gaceta Oficial 053 Extraordinaria de 11 de diciembre de 2012.

Art. 4. Las cooperativas se sustentan en los principios siguientes:

a) Voluntariedad: La incorporación y permanencia de los socios en la cooperativa es libre y voluntaria.

b) Cooperación y ayuda mutua: Todos los socios trabajan y se prestan ayuda y colaboración entre sí, para alcanzar los objetivos de la cooperativa.

c) Decisión colectiva e igualdad de derechos de los socios: Los actos que rigen la vida económica y social de la cooperativa se analizan y deciden en forma democrática por los socios, que participan en la toma de decisiones con iguales derechos.

d) Autonomía y sustentabilidad Económica: Las obligaciones se cubren con los ingresos. Pagados los tributos establecidos, crean los fondos y las utilidades se reparten entre sus socios en proporción a su contribución al trabajo.

e) Disciplina Cooperativista: Todos los socios aportan su trabajo en la cooperativa; conocen, cumplen y acatan conscientemente las disposiciones que regulan su actividad, así como los acuerdos de sus órganos de dirección y administración, y demás regulaciones que sean de aplicación a la cooperativa.

f) Responsabilidad social, contribución al desarrollo planificado de la economía y al bienestar de sus socios y familiares: Los planes de las cooperativas tienen como objetivo contribuir al desarrollo económico y social sostenible de la nación, proteger el medio ambiente, desarrollar sus actividades sin ánimo especulativo y garantizar el cumplimiento disciplinado de las obligaciones fiscales y otras. 
que sucede en la Ley 95/2002 se incluyen cuestiones que evidencian la participación económica de los asociados.

Así, al disponer que los socios trabajan y se prestan ayuda y colaboración entre sí, para alcanzar los objetivos de la cooperativa, satisfacer las necesidades materiales, de capacitación, sociales, culturales, morales y espirituales de sus socios y familiares, y para ellos conocen, cumplen y acatan conscientemente las disposiciones que regulan su actividad, se demuestra que entre otras cuestiones caben aquí los asuntos económicos.

Por otra parte, dentro de la decisión colectiva e igualdad de derechos de los socios, se establece que la vida económica y social de la cooperativa se analiza y decide en forma democrática por los socios, que participan en la toma de decisiones con iguales derechos. Estos elementos refuerzan el hecho de que el capital es accesorio a la persona en este tipo de entidades pues rige el principio de un socio un voto (igualdad).

Por último destacar que como parte de la autonomía y sustentabilidad económica se dispone que las cooperativas luego del pago de los tributos establecidos, crean los fondos y las utilidades se reparten entre sus socios en proporción a su contribución al trabajo. Elementos estos que constituyen manifestaciones concretas de la participación económica de los socios.

Por tanto, no existe en el DLCC (Decreto Ley 305/2012) ningún principio equivalente al de participación económica de los miembros en cuanto contribuyen al capital de la cooperativa y la controlan, recibiendo una compensación limitada, en su caso, sobre el capital suscrito. Sin embargo, sí se reconoce un reparto de las utilidades proporcional al trabajo de los socios en la cooperativa, al mismo tiempo que una de las menciones a reflejar en los estatutos será el monto del aporte dinerario de cada socio al capital del trabajo ${ }^{35}$.

En resumen, las normas cooperativas cubanas, no regulan de manera sistémica los principios cooperativos, no reconociéndose en ninguna de ellas a la participación económica de los asociados de manera

Trabajan por fomentar la cultura cooperativista y por las satisfacciones de las necesidades materiales, de capacitación, sociales, culturales, morales y espirituales de sus socios y familiares.

g) Colaboración y cooperación entre cooperativas y con otras entidades: Las cooperativas se relacionan entre sí y con otras entidades estatales o no, mediante contratos, convenios de colaboración, intercambio de experiencias y otras actividades lícitas.

35 MARÍN HITA, L.: Las cooperativas no agropecuarias en Cuba. En Revista de Estudios Cooperativos (REVESCO) Volumen 115, ISSN-e 1885-8031, Madrid, 2014. p. 135. 
específica, no obstante se evidencian rasgos de este través del análisis de otras reglas como la cooperación y ayuda mutua, disciplina cooperativista y autonomía y sustentabilidad económica.

\section{El capital social cooperativo en la legislación cubana ¿manifestación del principio de participación económica de los socios?}

La normativa vigente en Cuba, tanto para las cooperativas agrarias - Ley 95 de fecha 2 de noviembre de 2002 «Ley de Cooperativas de Producción Agropecuaria y de Créditos y Servicios» y normas subordinadas- como para las no agropecuarias - Decreto Ley 305 «De las Cooperativas no Agropecuarias» de fecha 15 de noviembre de 2012 y complementarias-, no regulan de manera sistémica al capital social cooperativo. ${ }^{36}$

En el caso de la Ley 95 de fecha 2 de noviembre de 2002 «Ley de Cooperativas de Producción Agropecuaria y de Créditos y Servicios», y normas subordinadas, no reconocen expresamente la institución capital social cooperativo, aunque si regulan la necesidad de las aportaciones de los socios para conformar el patrimonio cooperativo - concepto que incluye al capital social - las que pueden consistir en tierras, los demás bienes agropecuarios, instalaciones, medios culturales, recreativos

Se confunde, por tanto, la capital social con patrimonio, lo que provoca que no se reconozcan las especificidades teórico-jurídicas del capital social, como son la forma en que este debe integrarse, formalizarse, los documentos que avalan las aportaciones, etc. elementos de vital importancia en la vida interna de las cooperativas, dando lugar a conflictos ente los socios y de estos con la cooperativa, debido a la falta de claridad de la ley. ${ }^{37}$

36 La inexistencia de una norma general para las cooperativas provoca en la mayoría de los casos que no exista sistematicidad en las instituciones reconocidas en tales normas, tal es el caso del capital social. Por tanto, a criterio del autor sería favorable la aprobación en Cuba de una Ley de Cooperativas de manera unitaria, que las regule de forma integral, pues las cooperativas deben regirse por una noma de carácter general, sin importar el objeto social que desarrollen. Lo anterior no prohíbe que se aprueben de igual manera disposiciones que reconozcan reglas de manera específicas para los diversos tipos cooperativos.

37 Art. 32 a) Ley 95 de fecha 2 de noviembre de 2002 «Ley de Cooperativas de Producción Agropecuaria y de Créditos y Servicios», COLECTIVO DE AUTORES.: Temas de Derecho Agrario Cubano Tomo II. Selección Legislativa de Derecho Agrario Cubano. Volumen 1. Editorial Félix Varela, La Habana, 2007. 
Esta normativa reconoce el derecho de los socios o sus herederos a recibir el correspondiente pago por las aportaciones realizadas, según tasación oficial ${ }^{38}$.

Por otra parte establece que los miembros de las cooperativas que hayan aportado tierras y otros bienes agropecuarios -instrumentos de trabajo, animales, medios de carga - y que por cualquier motivo causen baja de ésta o en caso de disolución, sólo tienen derecho al cobro del importe no amortizado, es decir, de lo que hasta ese momento no habían recibido de acuerdo a lo aportado y de otros adeudos que con ellos tenga la cooperativa ${ }^{39}$. Dicha cuestión debería ser decisión de la cooperativa en específico, a través de sus estatutos —en este caso reglamento interno-.

En el caso de la legislación para las Unidades Básicas de Producción Cooperativa tampoco reconoce de forma expresa el capital social cooperativo, en estas el patrimonio se integra en lo fundamental, de los créditos bancarios, y de derechos patrimoniales de los que es titular

38 Ley 95 de fecha 2 de noviembre de 2002 «Ley de Cooperativas de Producción Agropecuaria y de Créditos y Servicios», COLECTIVO DE AUTORES.: Temas de Derecho Agrario Cubano Tomo II. Selección Legislativa de Derecho Agrario Cubano. Volumen 1. Editorial Félix Varela, La Habana, 2007.

Art. 12. Los agricultores pequeños que hayan decidido asociarse en Cooperativas de Producción Agropecuaria tienen derecho al cobro de sus tierras y demás bienes agropecuarios, según tasación oficial efectuada al efecto, los que se incorporan en su totalidad al patrimonio de la cooperativa.

Art. 33. Los miembros de las cooperativas que hayan aportado tierras y otros bienes agropecuarios y que por cualquier motivo causen baja de ésta o en caso de disolución sólo tienen derecho al cobro del importe no amortizado y de otros adeudos que con ellos tenga la cooperativa.

ARTíCULO 37. En caso de fallecimiento del cooperativista se transmiten a sus herederos la amortización pendiente de pago por los bienes aportados, las utilidades no recibidas y los anticipos pendientes de pago.

Art. 47. Determinado el monto anual de las utilidades, después de deducir los fondos destinados a la reserva para cubrir contingencias y el pago del impuesto sobre utilidades, se destina obligatoriamente parte de aquellas para el pago de las tierras y bienes aportados por los cooperativistas.

39 Ley 95 de fecha 2 de noviembre de 2002 «Ley de Cooperativas de Producción Agropecuaria y de Créditos y Servicios», COLECTIVO DE AUTORES: Temas de Derecho Agrario Cubano Tomo II. Selección Legislativa de Derecho Agrario Cubano. Volumen 1. Editorial Félix Varela, La Habana, 2007.

Art. 33. Los miembros de las cooperativas que hayan aportado tierras y otros bienes agropecuarios y que por cualquier motivo causen baja de ésta o en caso de disolución sólo tienen derecho al cobro del importe no amortizado y de otros adeudos que con ellos tenga la cooperativa. 
como el usufructo. En esta normativa no se establecen las aportaciones de los socios y consecuentemente tampoco al capital social. ${ }^{40}$

Todo esto provoca que no estén delimitados los fundamentos del capital social cooperativo y consecuentemente no resulte clara su autonomía con respecto a otros recursos patrimoniales, lo que incluye cuál es su monto, qué elementos lo integran, cuál es su papel dentro de la cooperativa y cuál sea su destino en caso de extinción de la cooperativa o baja del socio.

Por último el Decreto Ley 305 «De las Cooperativas no Agropecuarias» de fecha 15 de noviembre de 2012, así como el Decreto 309 «Reglamento de las Cooperativas no Agropecuarias de primer grado» (D 309/2012)de fecha 28 de noviembre de 2012, regulan el llamado capital de trabajo inicial, institución que se corresponde con lo estudiado aquí como capital social cooperativo, esto demuestra la diversidad de denominaciones en relación a esta institución.

Siguiendo a MESA TEJERA no existe una concepción clara del legislador, de la diferencia existente entre capital y patrimonio, lo cual se evidencia del análisis de la Sección Primera del capítulo V del Decreto 309, la que se denomina «Del Patrimonio» y sin embargo en su articulado regula, fundamentalmente, lo relativo al capital de la cooperativa. ${ }^{41}$

El patrimonio cooperativo, por tanto, está constituido por el conjunto de todos los bienes, derechos y obligaciones de que la cooperativa es titular en un momento determinado. Al tiempo de constituirse la

40 Resolución 574 del Ministro de la Agricultura de fecha 13 de agosto de 2012 « Reglamento General de las Unidades Básicas de Producción Cooperativa». Gaceta Oficial No. 037 Extraordinaria de 11 de septiembre de 2012.

Art. 13. El patrimonio de la UBPC está constituido por:

a) la maquinaria agrícola, los medios de transporte, los demás equipos e instrumentos de trabajo, las viviendas, instalaciones, viales internos y otros bienes adquiridos por compra o cualquier otro título y los creados por la UBPC;

b) Ios animales, las plantaciones, la producción agropecuaria y forestal y otras producciones que obtenga;

c) los recursos financieros; y

d) los derechos reconocidos en la Ley.

Art. 14. La tierra, los espejos de agua, los bosques naturales y artificiales y otros bienes que la UBPC reciba en usufructo no forman parte del patrimonio de estas y se prohíbe su arrendamiento, préstamo o utilización por terceros. El agua es patrimonio estatal y su empleo se hará de conformidad con el plan aprobado.

41 MESA TEJEDA, N.: Reflexiones críticas en torno a la regulación de las cooperativas no agropecuarias en Cuba. Boletín de la Asociación Internacional de Derecho Cooperativo ISSN: 1134-993X, Núm. 48/2014, Bilbao, p. 235. 
cooperativa suelen coincidir el patrimonio con el capital social, a no ser que esta además de las aportaciones, reciba otros recursos que pueden provenir de préstamos bancarios, donaciones, legados, etc. ${ }^{42}$

Muestra de la tesis anterior es el hecho de que el DL 305/2012 regula en el artículo 21.2 que el capital de trabajo inicial se constituye a partir del aporte dinerario que realizan los socios y de los créditos bancarios que se otorguen con ese objetivo. ${ }^{43}$ En el caso de los créditos forman parte del patrimonio y no del capital social.

El Reglamento del Decreto Ley establece que el capital de trabajo inicial de la cooperativa se aporta por los socios fundadores en pesos cubanos íntegramente en el acto de otorgamiento de la escritura fundacional o de forma aplazada, según se establezca en los estatutos, donde además se debe establecer el monto mínimo. ${ }^{44}$ En este artículo se establece que el capital se aporta, cuestión que no es correcta pues en realidad lo que se aporta es dinero, bienes, derechos y/o trabajo que en su conjunto integran el capital social cooperativo. ${ }^{45}$

Delimita, además, que las aportaciones dinerarias al capital de trabajo inicial se justifican ante notario mediante la certificación de su depósito, a favor de la Cooperativa en proceso de constitución, en un Banco del sistema bancario nacional cubano, ${ }^{46}$ sin delimitar que hacer cuando lo que se aporta sea distinto del dinero y que de igual manera se pueda expresar monetariamente.

En el análisis de esta normativa destaca la obligatoriedad de aportar dinero al capital de trabajo de la cooperativa, independientemente de otros bienes, trabajo y/o derechos que puedan aportarse, asunto

42 MESA TEJEDA, N,T; SOTO ALEMÁN, L; CAMPOS PÉREZ, Y; HERNÁNDEZ ATIENZA, M. Análisis del marco legal de las cooperativas no agropecuarias en Cuba», en VV.AA., El cooperativismo en Cuba. Situación actual y propuestas para su regulación y fomento. CIRIEC-España, Centro Internacional de Investigación e Información sobre la Economía Pública, Social y Cooperativa. Valencia, 2017, p. 120.

43 Art. 21.2 Decreto Ley 305 «De las Cooperativas no Agropecuarias» de fecha 15 de noviembre de 2012. Gaceta Oficial No. 053 Extraordinaria de 11 de diciembre de 2012.

44 Art.46 Decreto 309 «Reglamento de las Cooperativas no Agropecuarias de primer grado» de fecha 28 de noviembre de 2012. Gaceta Oficial No. 053 Extraordinaria de 11 de diciembre de 2012.

45 El Decreto Ley 309 Decreto 309 «Reglamento de las Cooperativas no Agropecuarias de primer grado» de fecha 28 de noviembre de 2012 en Cuba posee igual problemática pues en su artículo 46 establece que el capital de trabajo inicial de la Cooperativa se aporta por los socios fundadores en pesos cubanos íntegramente...

46 Art.48 Decreto 309 «Reglamento de las Cooperativas no Agropecuarias de primer grado» de fecha 28 de noviembre de 2012. Gaceta Oficial No. 053 Extraordinaria de 11 de diciembre de 2012. 
contradictorio pues el capital social cooperativo se integra, además, por las aportaciones no dinerarias, sin necesidad de aportar conjuntamente dinero.

En consecuencia, y debido a lo ambiguo de la norma, solo reconoce de forma expresa como parte del capital social cooperativo, a los aportes dinerarios, quedando fuera los aportes de bienes, derechos y trabajo que también pueden ser expresados monetariamente, pues forman parte del activo con que cuenta la cooperativa.

Sin embargo, cuando establece que los socios participen obligatoriamente con su trabajo se delimita que debe ser con independencia de cualquier otro aporte hecho sin declarar la naturaleza de este. En consecuencia no se establece la forma en que los aportes no dinerarios deben valorarse, lo que puede provocar una estimación incorrecta de ese determinado bien, derecho, trabajo o servicio y al final esto represente un perjuicio para el patrimonio y por ende para la cooperativa en sí.

Otro punto importante en este examen, es que la legislación relativa al cooperativismo no agropecuario no establece ninguna disposición referente al derecho de los socios al cobro de intereses o amortización por lo aportado-contrario a lo que dispone la normativa cooperativa agraria, cuestión que puede contribuir al desinterés de los sujetos por formar parte y aportar a una cooperativa.

Se puede, en fin, delimitar que pese a que estas cuestiones no gozan de un total regulación o sistematicidad en el contexto cubano no es menos cierto que el capital social cooperativo y en general el patrimonio han constituido en Cuba formas de participación de los socios, y tal vez de las más importantes. Basta puntualizar, por ejemplo, que las tierras con que cuentan las Cooperativas de Producción Cooperativa, y que juegan un papel esencial en estas cooperativas y como consecuencia en el desarrollo agrario nacional, fueron aportadas por sus socios, además de que a partir de la participación económica los asociados contribuyen con la sustentabilidad de la cooperativa, la suya propia y sus familiares.

\section{Conclusiones}

En base a lo analizado anteriormente se puede concluir que:

1. Los principios cooperativos constituyen reglas que organizan y distinguen a las cooperativas, lo que se corrobora en la propia existencia de las cooperativas, su relación con otras cooperativas, el estado, organizaciones, la comunidad, y los socios. Aun 
y cuando están referidos a todos los ámbitos en que estas se desarrollan, de manera directa o indirecta trascienden a su gestión económica y ordenan la participación de los asociados en este sentido.

2. Los miembros de una cooperativa participan económicamente en dos sentidos; primero aportando al patrimonio - capital social- de la cooperativa y luego beneficiándose de la gestión económica desarrollada por esta. Este último aspecto se materializa a través de los anticipos, el retorno o utilidades y la conformación de los fondos sociales.

3. El capital social cooperativo constituye la suma de las aportaciones, obligatorias y voluntarias, de los asociados ya sea en el momento de la constitución de la misma o posteriormente, bien por la incorporación de nuevos miembros o como consecuencia de acuerdos de aumento de capital. Constituye una de las formas esenciales de participación económica de los asociados en una cooperativa.

4. Las normas cooperativas cubanas, no regulan de manera sistémica los principios cooperativos, no reconociéndose en ninguna de ellas a la participación económica de los asociados de manera específica, no obstante se evidencian rasgos de este través del análisis de otras reglas como la cooperación y ayuda mutua, disciplina cooperativista y autonomía y sustentabilidad económica.

5. Pese a que el capital social cooperativo no goza de un total y sistémica regulación en el contexto cubano, no es menos cierto que este y en general el patrimonio han constituido en Cuba formas de participación de los socios, y tal vez de las más importantes formas de participación. Basta puntualizar, que las tierras con que cuentan las Cooperativas de Producción Cooperativa, y que juegan un papel esencial en estas cooperativas y como consecuencia en el desarrollo agrario nacional, fueron aportadas por sus socios, además de que a partir de la participación económica los asociados contribuyen con la sustentabilidad de la cooperativa, la suya propia y sus familiares. 


\title{
VIII. Bibliografía y legislación
}

\author{
Textos y documentos
}

ALIANZA COOPERATIVA INTERNACIONAL. 2015. Notas de orientación para los principios cooperativos.

CARDOSO, A. y HAMAHN, M. 2004. Principios cooperativos: origem, evolução e influencia na legislação brasileira. III Encuentro de Investigadores en cooperativismo. Porto Alegre. Unisinos.

CELAYA ULLíBARRI, A. 2001. "Criterios básicos para una regulación legal del Capital en las Sociedades Cooperativas». Boletín de la Asociación Internacional de Derecho Cooperativo, No. 35. Consultado en http://baidc. revistas.deusto.es/article/view/896 en fecha 9 de diciembre de 2017.

CENTRO DE ESTUDIOS Y CAPACITACIÓN COOPERATIVA. 2005. Doctrina cooperativa. Programa de educación a distancia administración de empresas cooperativas. Costa Rica.

CRUZ REYES, J. y PIÑEIRO HARNECKER, C. 2011. ¿Qué es una cooperativa?, en Cooperativas y socialismo. Una mirada desde Cuba. Editorial Caminos, La Habana.

DABORMIDA, R. 1999. La disciplina degli organi sociali. Cooperative, consorzi, reaggruppamenti. Ipsoe, Roma.

GARCÍA MÜLLER, A. 2014. Derecho Cooperativo y de la Economía Social y Solidaria. Editorial Mérida, Buenos Aires.

GÓMEZ APARICIO, P. 2003. «El capital social en las sociedades cooperativas. Las normas sobre los aspectos contables de las sociedades cooperativas a la luz de los principios cooperativos». CIRIEC-España, Revista de Economía Pública, Social y Cooperativa, n. ${ }^{\circ} 45$. Consultado en: $h t t p: / / w w w . c i r i e c$ revistaeconomia.es/banco/03_Gomez_45.pdf En fecha 12 de noviembre de 2017.

INTENDENCIA DE CANELONES. 2010. Manual para cooperativas de trabajo asociado. Bases para la organización de una cooperativa de producción. Montevideo. Industria Gráfica Cooperativa (INGRACO).

JIMÉNEZ GUETHÓN, R. 2017. El desarrollo del cooperativismo en Cuba. Consultado en roa.ult.edu.cu/bitstream/123456789/2320/1/art_RJimenez3.pdf en fecha 14 de diciembre de 2017.

KAPLAN DE DRIMER, A. y DRIMER, B. 1981. Las cooperativas. Fundamentos, historia, doctrina. Intercoop, Buenos Aires.

LUNA, G.F, E. 2001. «El capital en las sociedades cooperativas». Boletín de la Asociación Internacional de Derecho Cooperativo, No. 35. Consultado en http://baidc.revistas.deusto.es/article/view/896 en fecha 14 de diciembre de 2017.

MARÍN HITA, L. 2014. "Las cooperativas no agropecuarias en Cuba». En REVESCO. Revista de Estudios Cooperativos, No. 115, ISSN-e 1885-8031, Madrid. 
MESA TEJEDA, N. 2014. «Reflexiones críticas en torno a la regulación de las cooperativas no agropecuarias en Cuba». Boletín de la Asociación Internacional de Derecho Cooperativo ISSN: 1134-993X, Núm. 48, Bilbao.

MESA TEJEDA, N.T.; SOTO ALEMÁN, L.; CAMPOS PÉREZ, Y.; HERNÁNDEZ ATIENZA, M. 2017. "Análisis del marco legal de las cooperativas no agropecuarias en Cuba», en VV.AA., El cooperativismo en Cuba. Situación actual y propuestas para su regulación y fomento. CIRIEC-España, Centro Internacional de Investigación e Información sobre la Economía Pública, Social y Cooperativa. Valencia.

NOVA GONZÁLEZ, A. 2018. Las cooperativas agropecuarias en Cuba: 1959presente. Parte 4 Las cooperativas y la construcción socialista en Cuba. Consultado en http://www.actaf.co.cu/revistas/cooperativas/04-12coopsoci-cuba.pdf en fecha 12 d enero de 2018.

REYES LAVEGA, S. 2012. Las especiales características de las cooperativas. Fundación Friedrich Ebert, República Dominicana.

RIPPE, S. 2001. «El capital en las cooperativas». Boletín de la Asociación Internacional de Derecho Cooperativo, No.35. Consultado en http://baidc. revistas. deusto.es/article/view/896 en fecha de octubre de 2016.

RODRÍGUEZ MUSA, O. y HERNÁNDEZ AGUILAR, O. 2018. «Reflexiones sobre la implementación jurídica del principio de "participación económica de los asociados» en las cooperativas cubanas». En Boletín de la Asociación Internacional de Derecho Cooperativo, no. 52. ISSN-e: 2386-4893, Bilbao.

RODRÍGUEZ MUSA, O. y HERNÁNDEZ AGUILAR, O. 2015. «Las limitaciones jurídicas de la cooperativa en el socialismo. Perspectivas para el perfeccionamiento de su regulación en Cuba». REVESCO, Revista de estudios cooperativos, No. 117, pp. 99-124. ISSN: 1885-8031, Madrid.http://www. ciriec-revistaeconomia.es/banco/03_Gomez_45.pdf

URÍA, R. 1997. Derecho Mercantil. Editorial Marcial Pons, Madrid.

VILLEGAS CHADEZ, R. 1997. "El desarrollo del movimiento cooperativo en Cuba a la luz de los postulados de la Alianza Cooperativa Internacional (ACI)». REVESCO. Revista de Estudios Cooperativos, No 63. ISSN: 18858031. Madrid.

VUOTTO, M. 2016. "Las cooperativas no agropecuarias y la transformación económica en Cuba: políticas, procesos y estrategias». REVESCO, Revista de estudios cooperativos, No. 120, pp. 149-181. ISSN: 1885-8031, Madrid.

ZABALA SALAZAR, H. 2006. Defensa de los fondos sociales cooperativos: naturaleza, propósito y necesidad. Asociación antioqueña de cooperativas (CONFECOOP ANTIOQUIA). Consultado en: https://www.confecoopantioquia.coop/imagenes/descargas/FONDOSSOCIALES.pdf en fecha 31 de marzo de 2018. 


\section{Legislación}

CONVENCIÓN UNIVERSAL DE LOS DERECHOS HUMANOS. Consultado en www.un.org/es/documents/udhr/UDHR_booklet_SP_web.pdf en fecha 3 de mayo de 2018.

RECOMENDACIÓN 193 «Recomendación sobre la promoción de cooperativas», de fecha 20 de junio de 2002, de la Organización Internacional del Trabajo.

LEY DE COOPERATIVAS EN CANADÁ "Canadá Cooperatives Act» de 20 de octubre de 2010. Consultado en www.aciamericas.coop/-LegislacionCooperativa-en-las-Americas- en fecha 1 de agosto de 2017.

LEY GENERAL DE COOPERATIVAS DE CHILE, de 4 de noviembre de 2002. Consultado en www2.congreso.gob.pe/sicr/.../1.LEY-19832_04-NOV-2002.pdf en fecha 2 de mayo de 2018.

LEY GENERAL DE SOCIEDADES COOPERATIVAS de 30 de abril de 2001. México. Diario Oficial de la Federación 4 de Junio de 2001.

LEY MARCO PARA LAS COOPERATIVAS EN AMÉRICA LATINA. Consultado en www.aciamericas.coop/IMG/pdf/LeyMarcoAL.pdf en fecha 15 de enero de 2018.

LEY No. 95 «Ley de Cooperativas de Producción Agropecuarias y de Créditos y Servicios» de 2 de noviembre del 2002, Colectivo de Autores.: Temas de Derecho Agrario Cubano Tomo II. Selección Legislativa de Derecho Agrario Cubano. Volumen 1. Editorial Félix Varela, La Habana, 2007.

DECRETO-LEY N. ${ }^{\circ} 305$ "De las Cooperativas no Agropecuarias» de fecha 15 de noviembre de 2012. Gaceta Oficial 053 Extraordinaria de 11 de diciembre de 2012.

DECRETO-LEY N. ${ }^{\circ} 306$ «Del Régimen Especial de Seguridad Social de los socios de las Cooperativas no Agropecuarias» de fecha 15 de noviembre de 2012. Gaceta Oficial 053 Extraordinaria de 11 de diciembre de 2012.

DECRETO N. ${ }^{\circ} 309$ «Reglamento de las Cooperativas no Agropecuarias de primer grado» de fecha 28 de noviembre de 2012. Gaceta Oficial 053 Extraordinaria de 11 de diciembre de 2012.

RESOLUCIÓN 574 del Ministro de la Agricultura de fecha 13 de agosto de 2012 «Reglamento General de las Unidades Básicas de Producción Cooperativa». Gaceta Oficial No. 037 Extraordinaria de 11 de septiembre de 2012. 


\section{Derechos de autor}

El Boletín de la Asociación Internacional de Derecho Cooperativo es una revista de acceso abierto lo que significa que es de libre acceso en su integridad inmediatamente después de la publicación de cada número. Se permite su lectura, la búsqueda, descarga, distribución y reutilización legal en cualquier tipo de soporte sólo para fines no comerciales y según lo previsto por la ley; sin la previa autorización de la Editorial (Universidad de Deusto) o el autor, siempre que la obra original sea debidamente citada (número, año, páginas y DOI si procede) y cualquier cambio en el original esté claramente indicado.

\section{Copyright}

The International Association of Cooperative Law Journal is an Open Access journal which means that it is free for full and immediate access, reading, search, download, distribution, and lawful reuse in any medium only for non-commercial purposes, without prior permission from the Publisher or the author; provided the original work is properly cited and any changes to the original are clearly indicated. 